\title{
Prevalence of energy poverty in Japan: A comprehensive analysis of energy poverty vulnerabilities
}

\author{
Raúl Castaño-Rosa $^{\text {a,b, }}$, Shinichiro Okushima ${ }^{\text {c, *** }}$ \\ ${ }^{a}$ Universidad Carlos III de Madrid, Avenue of the University, 30 28911, Leganés, Spain \\ ${ }^{\mathrm{b}}$ Sustainable Housing Design Research Group, Built Environment Faculty, Tampere University, Finland \\ ${ }^{c}$ Graduate School of Systems and Information Engineering, University of Tsukuba, 1-1-1, Ten-nodai, Tsukuba-science-city, Ibaraki, 305-8573, Japan
}

\section{A R T I C L E I N F O}

\section{Keywords:}

Energy access

Energy justice

Energy poverty

Energy transition

Fuel poverty

Japan

\begin{abstract}
A B S T R A C T
Energy poverty, defined as the inability to fulfil adequate levels of domestic energy services, has been analysed in Japan previously. However, neither policy agendas nor official definitions of energy poverty have been established yet, resulting in the neglect of energy-poor households and other relevant aspects of this issue. This study is the first to examine the contextual factors of energy poverty in Japan, through the perspective of energy poverty vulnerabilities. The study uses a new multidimensional approach, covering the issues of affordability and accessibility to different forms of energy, as well as the effects of new technologies on the risk of energy poverty. The study develops several unexplored issues in previous literature, such as access to low-carbon energy as an issue in developed countries. The results highlight the role of location, infrastructure and household characteristics in influencing the risk of suffering energy poverty in Japan. The seasonality of energy poverty in Japan is also analysed, revealing higher rates of energy poverty in the northern regions during winter and in the southernmost region during summer. Finally, the impact of the ongoing energy transition from fossil fuels to renewable energy on energy poverty is discussed.
\end{abstract}

\section{Introduction}

Energy poverty (EP), broadly understood as the inability to achieve a socially and materially sufficient level of domestic energy services [1], has traditionally been studied across the EU [2-4]. Adequate levels of domestic energy services, such as space heating and cooling, water heating, lighting, cooking, usage of home appliances, and even ICT usage, are considered as essential for guaranteeing a decent standard of living for the citizens, and even requisites for fully realising their potential in their own lives. ${ }^{1}$ Furthermore, the relationship between physical and mental health issues and EP has been actively studied by researchers across the EU; for instance, burns and fires from candles or other unconventional heating systems [5], chronic cardiovascular and respiratory illnesses [6], exacerbation of other chronic health conditions
[7] and poor nutrition [8]. Deaths are known to occur when energy-poor households are disconnected from energy services for non-payment, mainly due to the impacts of extreme temperatures on the elderly (i.e. respiratory and renal diseases, epilepsy, etc.) [9].

Unlike in the EU, EP studies in Asia have been limited in terms of both quality and quantity. However, recent exploratory studies, such as in Japan [10-13], China [14,15], Hong Kong [16] and India [17,18], have increasingly examined this issue. Japan, the setting of this study, is one of the most developed countries in the world, continuously progressing on technological and national economic fronts. Furthermore, It is known for its healthier population than those in other OECD countries due to the low rates of risky health behaviour (e.g. drinking and smoking) and longer life expectancy $[19,20]$. However, studies have reported concerns regarding EP in Japan, with the prevalence of EP

\footnotetext{
Abbreviations: EP, Energy Poverty; EPP, Energy Poverty Premium; EU, European Union; FIT, Feed-in Tariff; FP, Fuel Poverty; GEJE, Great East Japan Earthquake;

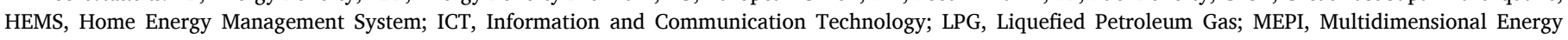
Poverty Index; OECD, Organisation for Economic Co-operation and Development.

* Corresponding author. University Carlos III of Madrid, Avenue of the University, 30 28911, Leganés, Spain.

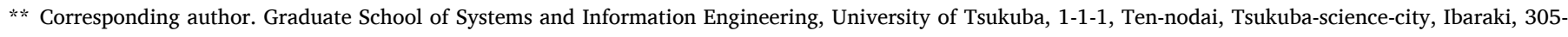
8573, Japan.

E-mail addresses: raulcastano90@gmail.com (R. Castaño-Rosa), okushima@sk.tsukuba.ac.jp (S. Okushima).

${ }^{1}$ See 'What is energy poverty?' in Ref. [2] (https://www.energypoverty.eu/about/what-energy-poverty).
} 
increasing especially after the Great East Japan Earthquake (GEJE) and the Fukushima nuclear accident $[10,11]$. A considerable number of people depend on kerosene for fulfilling their energy needs for winter heating; generating concerns regarding a possible adverse impact on the low-carbon transition policy $[12,13]$. Moreover, Japan faces new challenges with regard to the existing health gaps between regions and socio-economic groups, which has expanded in the last 25 years [19-22]. In this respect, the Japanese government has set the target of reducing existing health gaps between regions in the second term of the Health Japan 21 strategy [20]. While a direct relationship between health and EP in Japan has not been studied, some studies have indicated a possible relationship between physical health and indoor air quality in winter, which depends on fuel-use types and the quality of heating appliances in the northern region of Japan [23]. Despite the considerable evidence on EP, a policy agenda related to EP is yet to be established in Japan, which prevents relevant aspects of this issue from being addressed in an effective and consistent manner.

In order to design effective measures for EP, this study is focused on learning from past experiences in Europe, and deeply analyses the background factors of EP (henceforth referred to as EP vulnerabilities), ${ }^{2}$ along with the understanding of EP prevalence, which has already been noted in previous literature. In this context, the study extensively explores the issue of EP in Japan, utilising an extended version of the multiple-indicator approach developed by Castaño-Rosa et al. [3], which examined 6 key drivers of EP, based on recent European EP experiences. More specifically, this study analyses 12 vulnerability factors of EP in the Japanese context, in line with the three pillars of affordability, accessibility and new technologies, with the third pillar (new technologies) being a novel aspect of this study. The results of this EP vulnerability analysis will help to understand EP vulnerabilities in Japan and, consequently, to develop effective policies on EP-related issues.

Furthermore, this study has examined several unexplored issues in EP research: The regional and seasonal characteristics of EP and the regional gaps in access to low-carbon energy sources. While such energy access gaps have been overlooked as a determinant of EP in previous literature, the study demonstrates that they are strongly related to the EP phenomenon in Japan. Additionally, as indicated by Chapman and Okushima [13], the study notes that households in EP are likely to be excluded from the ongoing low-carbon transition in Japan due to little or no access to solar-power technology. Similarly, people living in off-gas grid areas are considered disadvantageous in terms of energy affordability, since natural gas is less expensive and is a lower-carbon energy source than LPG in Japan, whose disadvantages will be exacerbated by future deep carbon mitigation policies [12]. This study investigates the role of regional differences in accessibility to low(er)-carbon energy in determining the regional and seasonal EP prevalence in Japan, discussing the potential social exclusions related to EP and the necessary policy for an inclusive low-carbon energy transition.

The remainder of this paper is organised as follows: A first-time comprehensive literature review of Japanese EP-related studies is provided in Section 2. In Section 3, the theoretical framework for analysing EP vulnerability in Japan is presented. In Section 4, the EP vulnerability is investigated for the first time in each Japanese region, followed by an examination of the relationship between EP and the 12 vulnerability factors defined in the proposed theoretical approach with regard to affordability, accessibility and new technologies. Section 5 discusses the ongoing energy transition from fossil fuels to renewable energy from the perspective of EP vulnerability. The final section presents concluding remarks.

\footnotetext{
2 This study uses the term 'EP vulnerabilities' or 'EP vulnerability factors' as a set of contextual drivers or conditions which would possibly lead to a situation of $\mathrm{EP}[1,4]$.
}

\section{Energy poverty in Japan}

This section provides a comprehensive review of existing works that have already been conducted in Japan. To provide a clear narrative on the key themes addressed and gaps located in the existing research, Table 1 summarises key innovations and gaps from the analysis at the end of this section.

The term 'EP' can be used interchangeably with the Fuel Poverty (FP), as both terms come to define 'the propensity of an individual to become incapable of securing a materially and socially needed level of energy service in the home' [24,25]. In this respect, this study uses both terms with the same meaning. While some decades have passed since the seminal work on EP by Boardman [26], EP is yet to be well recognised in Japan as an independent phenomenon distinct from income or monetary poverty. It was not until the mid-2010s when the first EP study appeared in academic journals. Okushima [10] analysed EP prevalence in Japan from 2004 to 2013, focusing on the period around the Great East Japan Earthquake (GEJE). The study employed the $10 \%$ measure and indicated that EP had been aggravated during the period; Mother-child and single-elderly households were considered within those groups that were most vulnerable to EP; Energy price escalation was a major driver of EP increase after the GEJE and the Fukushima nuclear accident in 2011. This study established that the three factors that Boardman [26] focused on, namely energy price, low income, and energy efficiency of housing, were also significant in the Japanese context. Notably, the $10 \%$ measure in this study was based on the actual energy consumption in

Table 1

Analysis of innovations and gaps of existing research on EP-related issues in Japan (in chronological order).

\begin{tabular}{|c|c|c|}
\hline Reference & Innovation & Gaps \\
\hline Okushima (2016) [10] & $\begin{array}{l}\text { First analysis of EP in Japan } \\
\text { before and after the GEJE. }\end{array}$ & $\begin{array}{l}\text { No regional analysis. It } \\
\text { only provides annual } \\
\text { and winter estimates. }\end{array}$ \\
\hline Okushima (2017) [11] & $\begin{array}{l}\text { Development of a } \\
\text { multidimensional EP index } \\
\text { (MEPI), specifically focused } \\
\text { on EP in winter. }\end{array}$ & $\begin{array}{l}\text { No regional analysis. It } \\
\text { only provides annual } \\
\text { and winter estimates. }\end{array}$ \\
\hline $\begin{array}{l}\text { Tokyo Metropolitan } \\
\text { University Research } \\
\text { Center for Child and } \\
\text { Adolescent Poverty } \\
\text { (2017) [35] }\end{array}$ & $\begin{array}{l}\text { Report (from a survey) of } \\
\text { households with arrears in } \\
\text { utility bills within some } \\
\text { areas of Tokyo. }\end{array}$ & $\begin{array}{l}\text { It is not an EP study, as } \\
\text { it focuses on child } \\
\text { poverty. }\end{array}$ \\
\hline Konno et al. (2018) [32] & $\begin{array}{l}\text { Analysis of EP in some areas } \\
\text { in Hokkaido using an } \\
\text { original questionnaire } \\
\text { survey. }\end{array}$ & $\begin{array}{l}\text { Small sample size with a } \\
\text { low-response rate, } \\
\text { which possibly } \\
\text { introduced some bias. }\end{array}$ \\
\hline Yagita et al. (2019) [37] & $\begin{array}{l}\text { Qualitative research on } \\
\text { Japanese elderly } \\
\text { households. }\end{array}$ & $\begin{array}{l}\text { It is not an EP study, as } \\
\text { it focuses on energy } \\
\text { consumption by the } \\
\text { elderly. }\end{array}$ \\
\hline $\begin{array}{l}\text { National Institute of } \\
\text { Population and Social } \\
\text { Security Research } \\
\text { (2019) [36] }\end{array}$ & $\begin{array}{l}\text { Report (from a survey) of } \\
\text { households with utility } \\
\text { arrears in Japan. }\end{array}$ & $\begin{array}{l}\text { It is not an EP study, as } \\
\text { it focuses on social } \\
\text { security. }\end{array}$ \\
\hline Okushima (2019) [12] & $\begin{array}{l}\text { Development of a new } \\
\text { measurement approach with } \\
\text { multiple thresholds, } \\
\text { reflecting the diverse energy } \\
\text { needs of households. }\end{array}$ & $\begin{array}{l}\text { No seasonal analysis. } \\
\text { Difficult to compare } \\
\text { with the results given by } \\
\text { the affordability } \\
\text { measures. }\end{array}$ \\
\hline $\begin{array}{l}\text { Chapman and Okushima } \\
\text { (2019) [13] }\end{array}$ & $\begin{array}{l}\text { Analysis of EP in Japan by } \\
\text { using a subjective EP } \\
\text { measure. It also discusses } \\
\text { how an inclusive low-carbon } \\
\text { energy transition can be } \\
\text { implemented in Japan. }\end{array}$ & $\begin{array}{l}\text { It uses an internet-based } \\
\text { survey, which possibly } \\
\text { introduced some bias. }\end{array}$ \\
\hline $\begin{array}{l}\text { Tabata and Tsai (2020) } \\
\text { [33] }\end{array}$ & $\begin{array}{l}\text { Analysis of summer EP in } \\
\text { Japan. Examines the driving } \\
\text { factors of summer EP. }\end{array}$ & $\begin{array}{l}\text { It only considers } \\
\text { electricity expenditure } \\
\text { in the summer of } \\
\text { multiple-member } \\
\text { households before } \\
2004 \text {. }\end{array}$ \\
\hline
\end{tabular}


relation to the actual energy expenditure of the household. This feature may lead the 'hidden EP' issue (i.e. households do not have a minimum energy consumption due to the lack of monetary resources) [27] to be overlooked [28-30].

Okushima [10] mentioned that the $10 \%$ measure possibly identifies (relatively) wealthy households that essentially overuse energy as energy poor, without income cut-off points. To address this problem, Okushima [11] developed a multidimensional energy poverty index (MEPI) comprising three attributes (dimensions): Energy costs, income, and energy efficiency of housing. The study also demonstrated that since the 2000s, EP had been exacerbated in Japan and that mother-child and single-elderly households were highlighted as the most vulnerable groups from a multidimensional perspective of EP. Furthermore, the Japanese EP at the individual level was evaluated, indicating that the elderly living in energy-inefficient dwellings were the most vulnerable groups. However, this study did not provide a regional characterisation of EP and only focused on the annual and winter figures.

Later, Okushima [12] presented a new approach for measuring EP based on the underconsumption of domestic energy services, which can address the above 'hidden EP' phenomenon [27-30]; it is a type of relative poverty measure that uses calorific values (e.g. joule). Okushima [12] examined the regional EP in Japan during 2014-2015, reporting higher EP rates in the northern and southern regions, and the important role of kerosene in ensuring adequate energy services, specifically in northern Japan. This study also defined a new type of 'poverty premium' in Japan: The 'energy poverty premium' (EPP), which means that the unit cost of energy for domestic energy services is higher for the energy-poor than the affluent population. The results showed that energy-poor households paid more per unit for essential energy services. The research, however, did not provide seasonal figures, and the results are somewhat difficult to compare with other studies due to methodological differences.

As a study which applied a subjective EP measure in Japan, Chapman and Okushima [13] analysed the link between EP and an inclusive low-carbon energy transition. The results emphasised the need for an EP policy agenda that would recognise EP as an issue distinct from income poverty, highlighting the energy justice issues in Japan caused by the current low-carbon transition. Furthermore, the study noted that energy-poor households are not financially supported in the ongoing low-carbon transition, and hence are unable or unwilling to participate the transition. It concluded that EP policies should promote access to solar and low-carbon technologies among the most vulnerable groups to ensure an inclusive and just transition [31]. The research used an internet-based survey to collect households' evidence, but whose feature might be a limitation in the context of EP, as most vulnerable people do not generally use the internet.

Another type of study, Konno et al. [32], estimated EP prevalence by applying the $10 \%$ measure and using an original questionnaire survey in some areas in Hokkaido, reporting high EP rates (12-32\%) and highlighting the elderly households as being vulnerable to EP. This study emphasised the importance of housing energy (in)efficiency as a driving factor of EP in the cold-climate areas of Japan. However, the small sample size with a low-response rate was a possible limitation of this study.

A recent study, Tabata and Tsai [33], estimated the summer EP rates in Japan for 1989, 1994, 1999, and 2004, using the National Survey of Family Income and Expenditure [34]. By utilising the 10\% measure and the income threshold, it showed that Japan's summer EP rate was $0.93 \%$ in 2004, and that elderly households were most vulnerable to EP (with $1.9 \%$ of them being in EP). The reported EP rates were small, possibly because this research only considered the electricity costs of multiple-member households in summer, thus excluding the remaining energy costs of a household, in addition to excluding single-member households. Furthermore, the years analysed are dated before the GEJE.

In contrast to the above EP studies, the report of Tokyo Prefecture Child Living Conditions Survey targets the issue of child poverty, rather than EP [35]. However, this report also includes a survey of households' income situation which makes it possible to identify those who cannot pay their utility bills (electricity, gas, etc.) due to financial reasons. Arrears on utility bills are one of the four primary indicators of EP provided by the European EP Observatory [2]; therefore, they can be interpreted as EP in the context. The results revealed that in 2016, 3-6\% of single-parent households and $20-30 \%$ of the poor households with children had experienced arrears in electricity bills in the past year (with a similar result for gas payment arrears). Although this survey covered only families with children who lived in certain areas in Tokyo, the results showed a higher EP prevalence in Tokyo, the most developed and wealthy city in Japan. This study was focused on the analysis of child poverty and only covered households with children, making it difficult to provide a comprehensive analysis of the EP situation among different types of households in different regions.

The report of National Survey on Social Security and People's Life 2017 [36] also does not aim to investigate EP; however, this large survey measures arrears on utility bills, as in the case of the report of Tokyo Prefecture Child Living Conditions Survey [35]. This study showed that in total, $3.3 \%$ of households reported to have experienced arrears on electricity bills (and $3.4 \%$ gas arrears) in the past year due to financial reasons in Japan. Specifically, $15.0 \%$ and $17.7 \%$ of single-parent households (two generations) reported electricity and gas arrears, respectively, in the past year. While the rate of single-male-elderly households who reported arrears was low (3.5\% electricity, 3.4\% gas), more than $10 \%$ of these households reported their inability to keep their houses at an adequate temperature for financial reasons. This situation implies the possibility of 'hidden EP', where elderly households may reduce their energy use in order to afford to pay their bills [27-30].

Yagita et al. [37], while not examining the issue of EP itself, examined the characteristics of energy consumption in elderly households by conducting an interview survey of 40 elderly households. The results revealed the distinctive characteristics of Japanese elderly households, which might increase EP vulnerability: They prefer and heavily use kerosene stoves for winter heating even if they have air conditioners; they are attached to their old home appliances, thereby avoiding the newer and more energy-efficient ones; and they do not have the required awareness regarding energy saving or dwelling insulation improvement. A possible limitation of this study is its dependence on the small number of interviewees, leading to some difficulties in considering these results as representative.

Table 1 summarises the existing research on EP-related issues in Japan in chronological order, highlighting their innovations and gaps. Although EP has been analysed to some extent in Japan, studies are still inadequate in terms of quality and quantity, as compared to the EU studies [2-4,38], with very little regional analysis in light of climatic differences. Thus, further analysis on EP from a multidimensional perspective is required to provide a better understanding of how EP is experienced in the Japanese context. In this respect, this study goes beyond existing studies, which do not provide a comprehensive understanding of the different factors that affect EP, contributing to filling this research gap through the definition of a new theoretical approach to analyse EP vulnerability in Japan.

\section{Study framework and analysis definition}

This section presents the new theoretical framework proposed to analyse EP vulnerability in Japan, which is based on the multipleindicator approach developed by Castaño-Rosa et al. [3]. Before explaining the framework, the EP measure adopted to assess the current state of EP among the different Japanese regions is defined.

$\mathrm{EP}$ in Japan has recently been analysed using the multidimensional energy poverty index (MEPI) [11-13]. However, given the purpose of this study and the lack of data availability, the study considered that the $10 \%$ measure [38] is most feasible to analyse the regional characteristics of EP in Japan, covering both the affordability and accessibility to 
different forms of energy. Therefore, an adapted version of the $10 \%$ measure is utilised in this study to assess the regional EP rates, defined by equation (1):

$E P=\frac{Q}{N}=\frac{1}{N} \sum_{i=1}^{N} c\left(\frac{E C_{i}}{H I_{i}}>0.1\right)$

Here, $E P$ is the energy poverty rate, a type of the headcount ratio index; $Q$ is the number of energy-poor households; and $N$ is the total number of households. $c(\cdot)$ is an indicator function that takes a value of 1 if the condition in brackets is true and 0 if false. ECi is the actual expenditure of household $i$ for their domestic energy use (heating, cooling, water heating, cooking, usage of lights and appliances, excluding driving cars), and $H I i$ is the gross income of household $i$. The data on ECi and HIi were obtained from the anonymised information in the 2013-2017 Family Income and Expenditure Survey, conducted by the Statistics Bureau, Ministry of Internal Affairs and Communications, Japan. Thus, this study uses its original calculations utilising the aforementioned dataset provided by the Japanese government to estimate the EP rates. ${ }^{3}$

EP is a multidimensional issue with different attributes, such as accessibility [14,39], affordability [40,41], flexibility [42,43], energy efficiency [44,45], needs [46], and habits [47]. In Japan, there is neither a policy agenda nor a formal definition of EP, along with minimal studies on how to address vulnerability to EP. To bridge this gap, this study presents a new theoretical approach to better understand the vulnerability factors to EP in Japan (Fig. 1), which focuses on the affordability and accessibility aspects of EP, based on the multiple-indicator approach developed by Castaño-Rosa et al. [3]. Additionally, the concept of new technologies is introduced as a novel

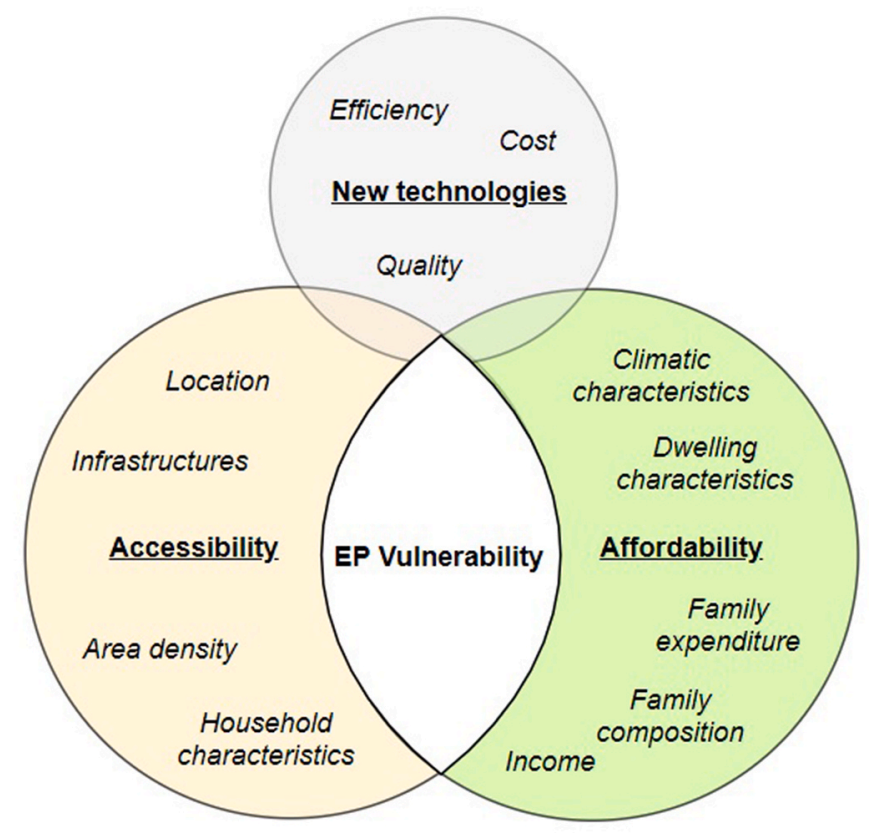

Fig. 1. Energy poverty vulnerability framework for Japan (authors' own contribution).

\footnotetext{
${ }^{3}$ Family Income and Expenditure Survey is the only governmental statistics that includes monthly expenditure data on domestic energy services in every month for each region in Japan. With it, the regional and seasonal EP in Japan can be analysed. However, it has a significant limitation in that this study can only evaluate the EP of households with two or more members, thereby excluding single-member households.
}

aspect, and its role as a driver of EP vulnerability is analysed. This study examines 12 vulnerability factors in line with the three aspects: Affordability, accessibility and new technologies.

Traditionally, the term affordability represents the inability of a household to satisfy adequate levels of domestic energy services, such as heating, cooling, hot water, and the use of electrical appliances, due to its poor monetary or dwelling situation. Building on the study of Castaño-Rosa et al. [3], energy affordability analysis considers factors such as income, expenditure, family composition, quality of dwelling and climatic conditions.

The term accessibility has traditionally been related to developing countries, where basic needs, including adequate access to energy, remain out of reach, leading to social, educational and health issues [1, 48]. In this respect, based on the study conducted by Castaño-Rosa et al. [3], the location, infrastructure, fuel and equipment typologies, socioeconomic situation of households, and area density are considered in the analysis of energy access.

Finally, the term new technologies encompasses the energy-justice issue related not only to the lack of access of households to new lowcarbon technologies (e.g. solar panels) but also to all kinds of new energy-related technologies (e.g. smart meters), whose relation to EP has not been fully addressed in the literature yet. In this respect, the role that new technologies shall play in EP vulnerability, not only in technologically advanced developed countries but also in developed and fast developing countries in the forthcoming years, has been analysed in this study. Note that the limited research on the relationship between EP and access to new technologies is reflected in Fig. 1 with the small cutting part of the new technologies factor, which may increase as further studies and literature are provided. For this analysis, the study assumes that new technologies refer to all kinds of new equipment and low-carbon (or energy-saving) technologies designed by private companies to provide a better and more comfortable quality of life. While there are a few studies on this topic [49-52], this study provides new insights into the relationship between new technologies and the risk of suffering EP by building on interconnected studies. The manner in which people use new, energy-saving and/or low-carbon housing systems (efficiency), the ability of people to afford new, energy-saving and/or low-carbon housing systems (cost), and the effectiveness of new, energy-saving and/or low-carbon housing systems in reducing the risk of EP (quality), are the three vulnerability factors analysed as drivers to EP.

\section{Results and findings}

This section first presents the regional and seasonal EP prevalence for the Japanese regions. Second, EP vulnerability is analysed based on different factors, which have been classified into three groups affordability, accessibility and new technologies - as defined in the framework proposed in Section 3 (Fig. 1).

\subsection{EP prevalence in Japan}

First, the regional and seasonal characteristics of EP are assessed. According to the adapted 10\% measure explained in Section 3, Fig. 2 illustrates the Japanese EP trend from 2013 to 2017, showing EP prevalence in winter (February) and summer (August), respectively. The results clearly indicate the difference in EP prevalence between seasons. $^{4}$

Fig. 3 depicts in-depth the regional and seasonal rates of EP in Japan for 2017. The most relevant result is that the regional variation of EP rates depends on the season: Northern regions facing harsh winters have the highest EP rates in winter (e.g. Hokkaido, 24.5\%, and Tohoku,

\footnotetext{
${ }^{4}$ The declining trend of EP rates from 2015 to 2017 shown in Fig. 2 relates to the fall in international and domestic energy prices, which is consistent with the results of previous studies [12,13].
} 


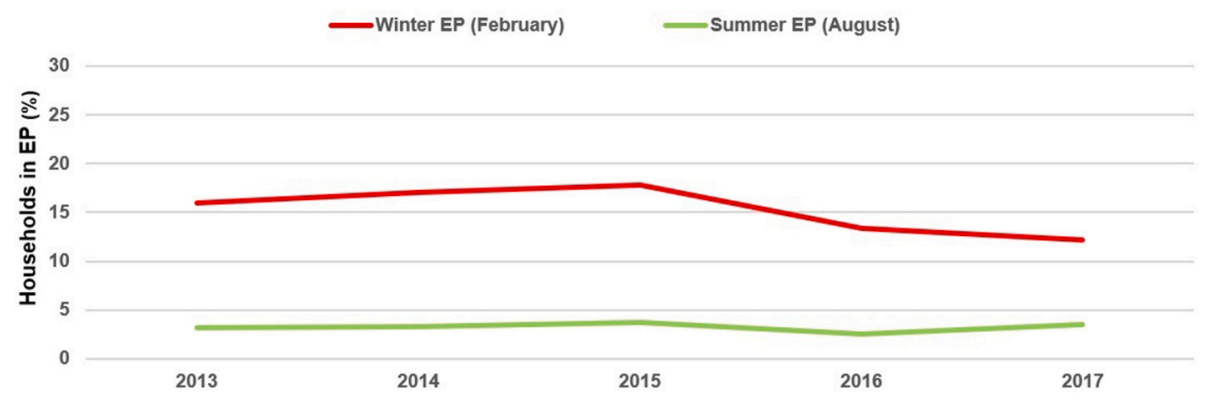

Fig. 2. Trends of EP rates in Japan according to the adapted $10 \%$ measure.

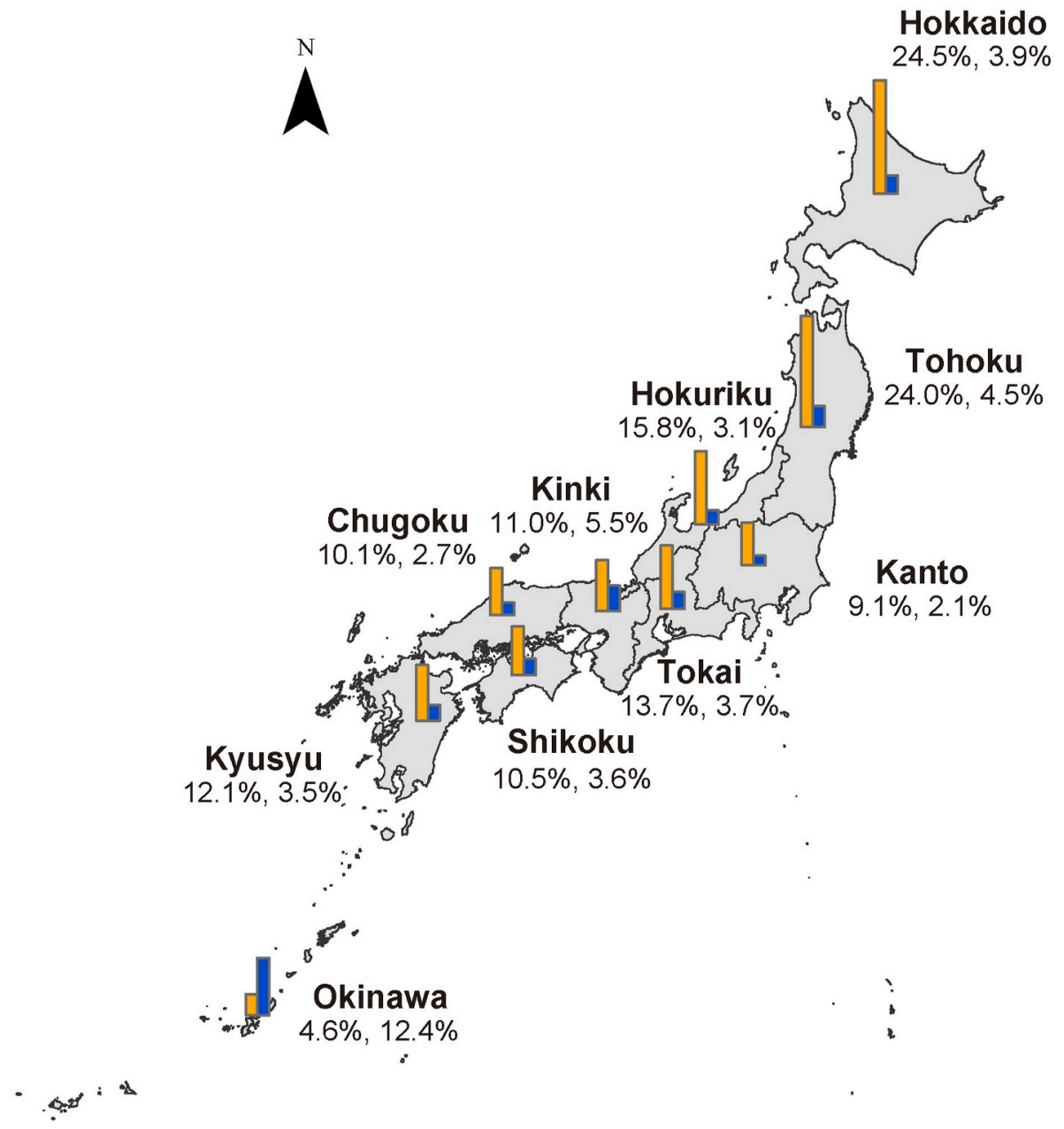

Fig. 3. EP prevalence in Japan (Orange bar: February 2017; Blue bar: August 2017).

$24.0 \%$ ), while the southernmost region, with mild winters but hot summers, has a higher summertime EP rate (e.g. Okinawa, 12.4\%). In this respect, it should be highlighted that although Okinawa has a very low EP rate during wintertime (4.6\%, compared to the average of $12.2 \%$ in Japan), it has the highest EP rate in summer (12.4\%, compared to the average of $3.5 \%$ in Japan). As Fig. 3 indicates, Japan is famous for its diverse climate (ranging from subarctic to subtropical), which has a major influence on the risk of EP, regionally and seasonally (see Ref. [12] for further details on the climatic differences in Japan).

\subsection{Analysis of EP vulnerability factors}

In this subsection, the relationship between EP and the 12 vulnerability factors defined in the proposed theoretical approach (see Fig. 1) is explained according to the three main pillars: affordability, accessibility and new technologies.

\subsubsection{Affordability}

As explained in Section 3, income, expenditure, family composition, quality of dwelling, and climatic conditions are the main factors considered in the affordability analysis.

Income: The household's monetary situation is a key factor determining vulnerability to EP, and has been well justified throughout the literature $[53,54]$. While the gap in regional income levels is not large in Japan [55], regions with lower-income levels appear to have higher EP rates. In this respect, Fig. 4a shows the relationship between the regional average income level and EP rates. Data for this analysis were obtained from the 2014 National Survey of Family Income and Expenditure [34]. 

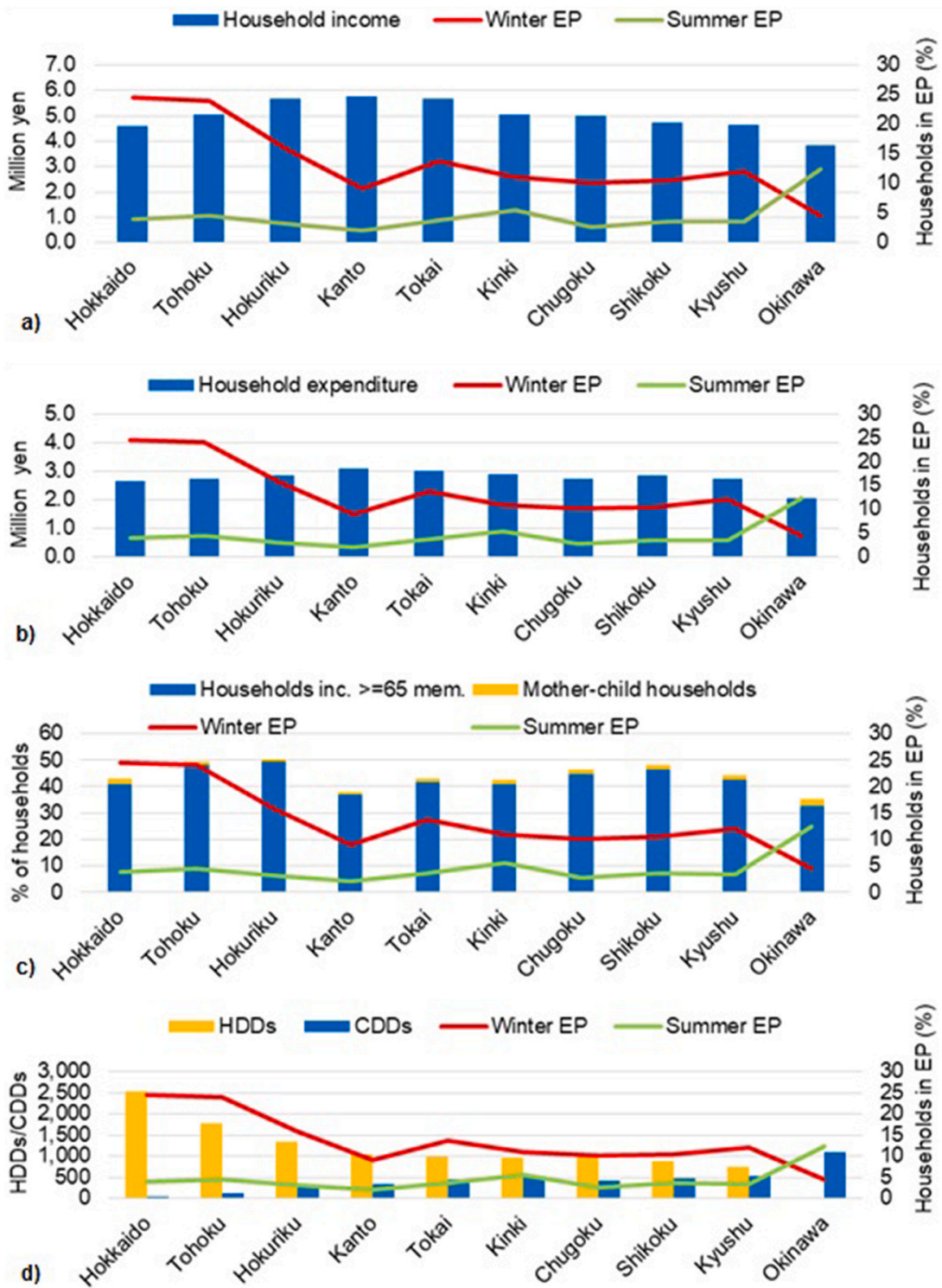

Fig. 4. Regional and seasonal EP rates with respect to a) income level, b) expenditure level, c) household composition and d) climatic characteristics.

Fig. 4a shows that regions with lower income levels have higher EP rates (specifically Hokkaido, Tohoku and Okinawa) than those with higher income levels (central regions). In terms of seasonality, the highest winter EP rates are observed in the northern regions of Hokkaido (24.5\%) and Tohoku (24.0\%). The southern region of Okinawa exhibits the highest EP rate in summer (12.4\%). Fig. 4a illustrates how Okinawa, with a lower income level than other regions, is the region with the highest EP rate in summer.

Expenditure: EP has traditionally been assessed considering either the gross or net income of the household. Gross income includes all the financial income that a household may obtain from any source. Net income means that all those expenditures that a household cannot use for paying their energy bills are excluded, leaving only the disposable amount a household can use to cover its basic energy services. In this respect, Fig. 4b shows the relationship between the households' expenditure levels and EP rates. Data for estimating households' regional average expenditure were obtained from the 2017 Family Income and Expenditure Survey [34]. The results show that the high expenditure levels in the central regions, specifically in Kanto (the most developed region with capital Tokyo), are well covered by their high-income levels (Fig. 4a) and, as a result, those regions have lower EP levels. On the contrary, Okinawa has the lowest expenditure as well as income level, resulting in it being most affected by EP in summer. Fig. 4b depicts the negative relationship between household expenditure levels and $\mathrm{EP}$ rates.

Composition of the family: Household composition has recently been shown to be a key determinant of EP $[46,56]$. In this respect, EU legislation obliges member states to protect vulnerable consumers [57], among which elderly and single-mother households, disabled people, pregnant women and unemployed people are considered to be the most vulnerable [58-60]. Fig. 4c, by using data from the 2015 Population Census [34], illustrates the relationship between EP and vulnerable groups (in terms of mother-child households and households including elderly members [65 years old or over]). Kanto, the region with fewer vulnerable groups, has much lower EP rates both in winter and summer. On the other hand, the northern regions of Tohoku and Hokuriku, with the highest percentages of vulnerable groups, have a higher risk of EP, specifically in winter. Okinawa has the lowest percentage of vulnerable groups, despite the highest percentage of mother-child households, as it is known to have a younger age structure. This implies that Okinawa's highest EP in summer is not attributable to the factor of family composition, but rather the other factors explained within this 
framework.

Dwelling characteristics: The year of construction, state of maintenance, ventilation and housing systems and energy rating are key factors in the energy efficiency of a dwelling and, consequently, in the energy consumption of the household $[44,61]$. While the energy conservation standards for housing were established in Japan as early as 1980, there are no official statistics that detail the energy-efficiency characteristics of existing building stock, thus making it difficult to obtain feasible data for this analysis. However, this study uses data on the dwelling ratio built before 1980 for each region, obtained from the 2013 Housing and Land Survey [34], to develop this analysis (Fig. 5). Although the level is high overall, Tohoku (27.3\%), Hokuriku (28.5\%), Chugoku (28.5\%) and Shikoku (28.4\%) represent regions with the highest ratios of dwellings built before 1980 (by means of old and [highly-possibly] energy-inefficient dwellings). Such features regarding housing quality in Japan, combined with the very cold climate in winter, and high temperatures in summer, possibly lead to a higher EP rate (Tohoku, 24.0\%, and Hokuriku, $15.8 \%$, in winter; and Okinawa, $12.4 \%$, in summer) as well as higher risks of health issues [23].

Climatic characteristics: The seasonal aspect of vulnerability to EP has recently been investigated, and is garnering the interest of governments in Europe $[62,63]$. In Japan, EP has been assessed during the wintertime or the whole year, resulting in regions with summer EP being overlooked (for instance, the Okinawa region). This study assesses the seasonality of EP in Japan by using the data on Heating Degree Days (HDDs, D14-14) and Cooling Degree Days (CDDs, D22-24) in 2017 from the Residential Energy Statistics Yearbook 2017 [64]. Fig. 4d shows that the regions with the highest values of HDDs (2520, in Hokkaido; and 1768, in Tohoku) also have the highest EP rates in winter $(24.5 \%$ and $24.0 \%$, respectively), in comparison with Okinawa, which has the lowest value of HDDs and EP rate (2 and 4.6\%, respectively). However, the analysis of CDDs shows that Okinawa has the highest value of CDDs as well as the highest EP rate in summer (1090 and 12.4\%, respectively); Hokkaido and Tohoku exhibit the lowest values of CDDs ( 40 and 134, respectively) and summer EP rates (3.9\% and 4.5\%, respectively). The figure shows that climatic factors are strongly related to the risk of EP in Japan, and hence should never be ignored when regionally analysing EP and its countermeasures [12].

\subsubsection{Accessibility}

For the energy accessibility analysis, factors, such as location, infrastructure, fuel and equipment typologies, socioeconomic situation of households and area density, are considered (see Section 3 for further details).

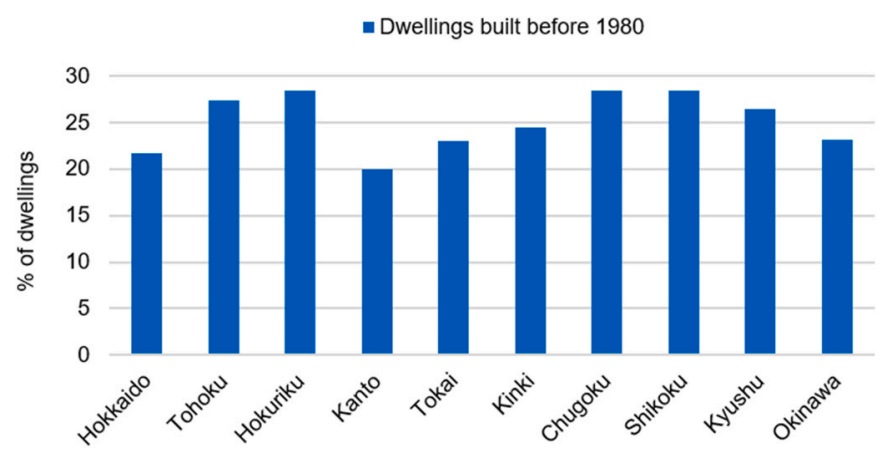

Fig. 5. Percentage of dwellings built before 1980 [34].

Location: The area where the home is located influences the household's energy performance directly or indirectly [39]. The available infrastructure and climatic characteristics in the location area are key factors that influence the risk of EP. This study shows the relationship between these factors and regional EP rates in Japan. Fig. 6a shows that people living in the most developed regions, such as Kanto and Kinki, have a higher possibility of accessing natural gas (city gas) than other regions. ${ }^{5}$ Fig. 7 illustrates the area where city gas is available to the residents (in orange), which in fact covers only $6 \%$ of the entire area in Japan, and is located mainly in urban areas. In conclusion, both figures show that people living in regions with the highest EP rates, such as Hokkaido, Tohoku and Okinawa, have limited access to natural gas, which introduces energy and spatial justice issues. People who do not have access to natural gas are in a disadvantageous position, and these historically and spatially embedded disadvantages (e.g. whether one lives in an on- or off-gas grid area) are significantly related to the presence of EP [12,48].

Additionally, the use of solar panels is presented in Fig. 6a: Only $7.5 \%$ of the Japanese households use solar panels in their dwellings. Chapman and Okushima [13] delivered a rationale for why solar deployment level is low in the Japanese households, listing several reasons, including low affordability, dwelling characteristics and rental clauses. It could be stated that the use of solar panels might effectively reduce energy bills, particularly in summer. Note that the southernmost region of Okinawa, with the highest EP rates in summer, also has a much lower deployment level for solar panels. Hokkaido, the region with the highest EP rates in winter, also has the lowest deployment level. Although it is known that there are potential barriers to the deployment of solar panels in dwellings in Japan [13], promoting the use of 'solar energy' among those households in EP, regardless of their own capacity of solar deployment, could considerably help alleviate EP.

Infrastructure/fuel types/equipment: One of the factors influencing the fuel type used for heating is the type of facilities that households can access, which is also related to the area where the house is located. Fig. 6b depicts household energy consumption by fuel type with respect to EP rates in $2017 .^{6}$ This shows that the use of kerosene (heating oil) is closely correlated with the climatic characteristics in each region, as kerosene is used for heating in winter, specifically in regions with harsh winters [12]. Thus, the northern regions of Hokkaido, Tohoku and Hokuriku exhibit the highest use of kerosene and the highest EP rates in winter and, consequently, may be at a higher risk for respiratory illnesses [23]. On the other hand, regions with higher use of city gas, mainly the central regions of Kanto, Tokai and Kinki, have lower EP rates. City gas is cheaper and has lower carbon emissions than LPG in Japan. Additionally, the trend in electricity consumption is relatively similar across all regions, mainly because of the generalised use of electric appliances by Japanese households. This study highlights the relationship between electricity consumption, non-use of solar panels and high EP rates. Okinawa has one of the highest shares of electricity consumption, lowest rates of solar panels deployment and highest EP rates in summer (Fig. 6a and b).

Household socioeconomic situation: The employment situation, due to its influence on household income, may be considered as a highly influential factor in EP [30]. However, only $2.8 \%$ of the population in Japan is unemployed and there is no significant regional difference (see Fig. $6 \mathrm{c}^{7}$ ). Comparing this with the unemployment situation in other European countries, such as Spain (14.1\%) or Greece (17.3\%) [66], this factor does not appear to be relevant for EP in Japan. In the Japanese context, the quality of employment, which can be by proxy described by the wage level and the educational level, has a significant influence on $\mathrm{EP}$, revealing large regional disparities. This study is the first to assess

\footnotetext{
5 Authors' own calculations by using anonymised information from the 2017 Survey on the Actual Conditions of Carbon Dioxide Emissions from Residential Sector, provided by the Ministry of the Environment, Japan [65].

6 Authors' own calculations by using anonymised information from the 2017 Survey on the Actual Conditions of Carbon Dioxide Emissions from Residential Sector, provided by the Ministry of the Environment, Japan [65].

7 Data were obtained from the 2017 Labour Force Survey [34] (Unemployment rate) and 2010 Population Census [34] (Educational level).
} 

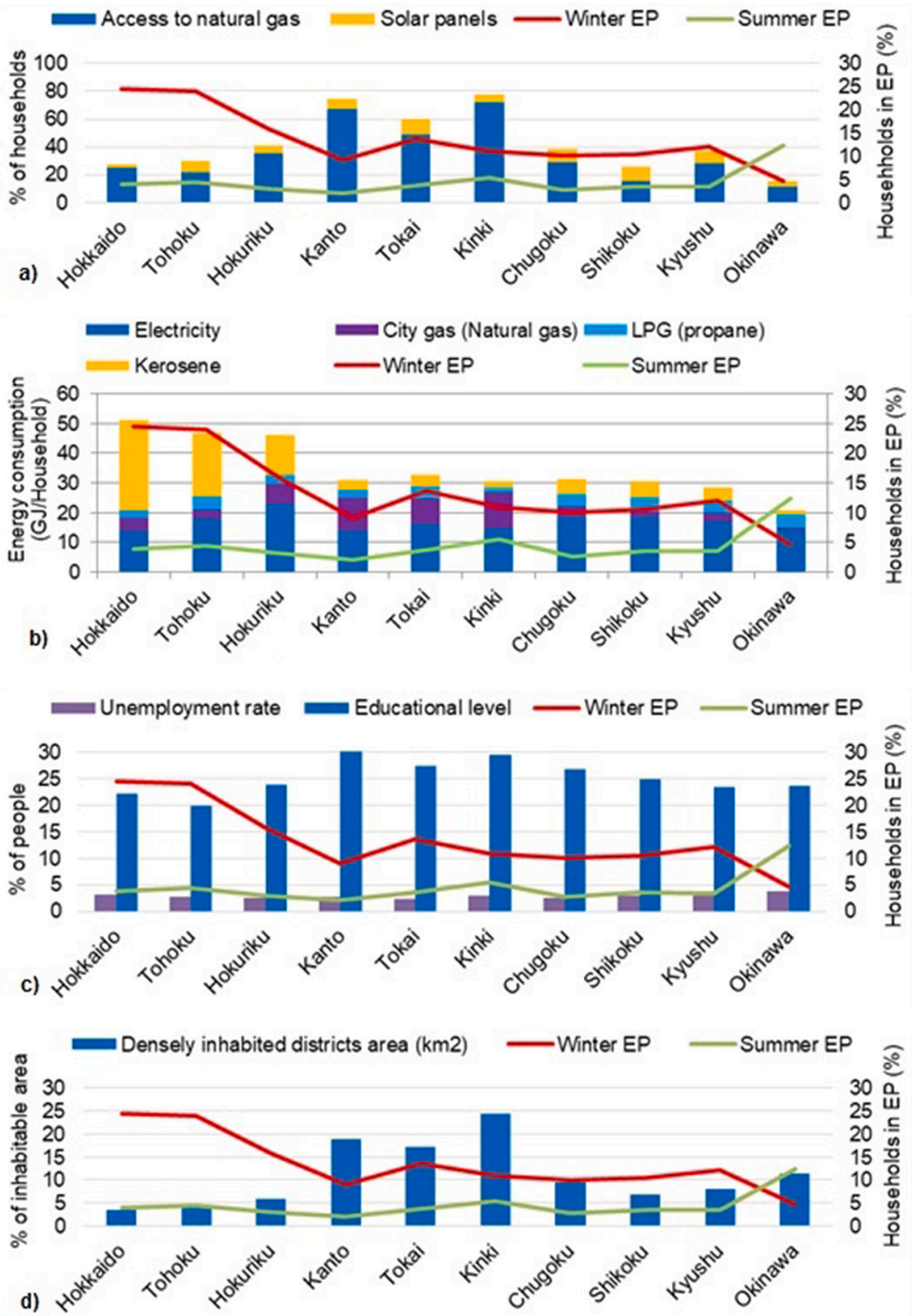

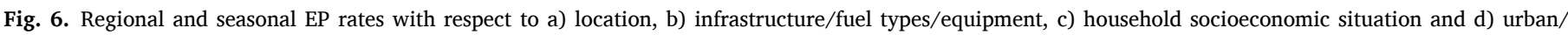
rural density.

the relationship between households' educational level and EP rates across Japan. Fig. $6 c$ presents the educational level by region (the population ratio that has completed junior college, college of technology, graduate school or university degree), indicating that the regions with lower educational levels (Hokkaido and Tohoku) have higher EP rates than those with higher educational levels. Okinawa, a characteristic region in Japan, also follows this tendency. This is also associated with social exclusion, wherein young people tend to attain low academic results due to low income, poor quality of dwelling and an inadequate environment, perpetuating the cycle of poverty [67].

Urban/rural density: The lack of efficient and well-maintained infrastructure considerably affects the possibility of households maintaining an adequate level of energy services [68]. The type of facilities and systems in the house is closely related to the urbanisation level in the area where the house is located (rural or urban). The relationship between area density and EP has also been evaluated [69], revealing that rural areas have higher EP rates than urban areas, as generally urban households are able to change their energy suppliers, housing systems or decide on the type of fuel used. Fig. 6d, using data from the System of Social and Demographic Statistics [34], provides the relationship between urban/rural density and EP across Japan in 2015. The results show that the regions that are largely rural or have a lower urbanisation (Hokkaido, Tohoku and Hokuriku) are also regions with higher EP rates. Generally, people living in remote areas are unable to access cheaper and more efficient fuel types (city gas in the case of Japan). As a result, they use more expensive fuel types (than people living in urban areas), possibly leading to a higher prevalence of EP in less developed areas [70]. Notably, the summer EP does not follow this tendency since the main fuel type used for cooling is electricity, which most people have access to in developed countries such as Japan, unlike in developing countries, where access to electricity is the central issue [71]. Thus, the urbanisation level in Japan has a lower influence on EP rates in summer, rather than the other factors, such as income level.

\subsubsection{New technologies}

Finally, this subsection, a novel aspect of this study, provides an 


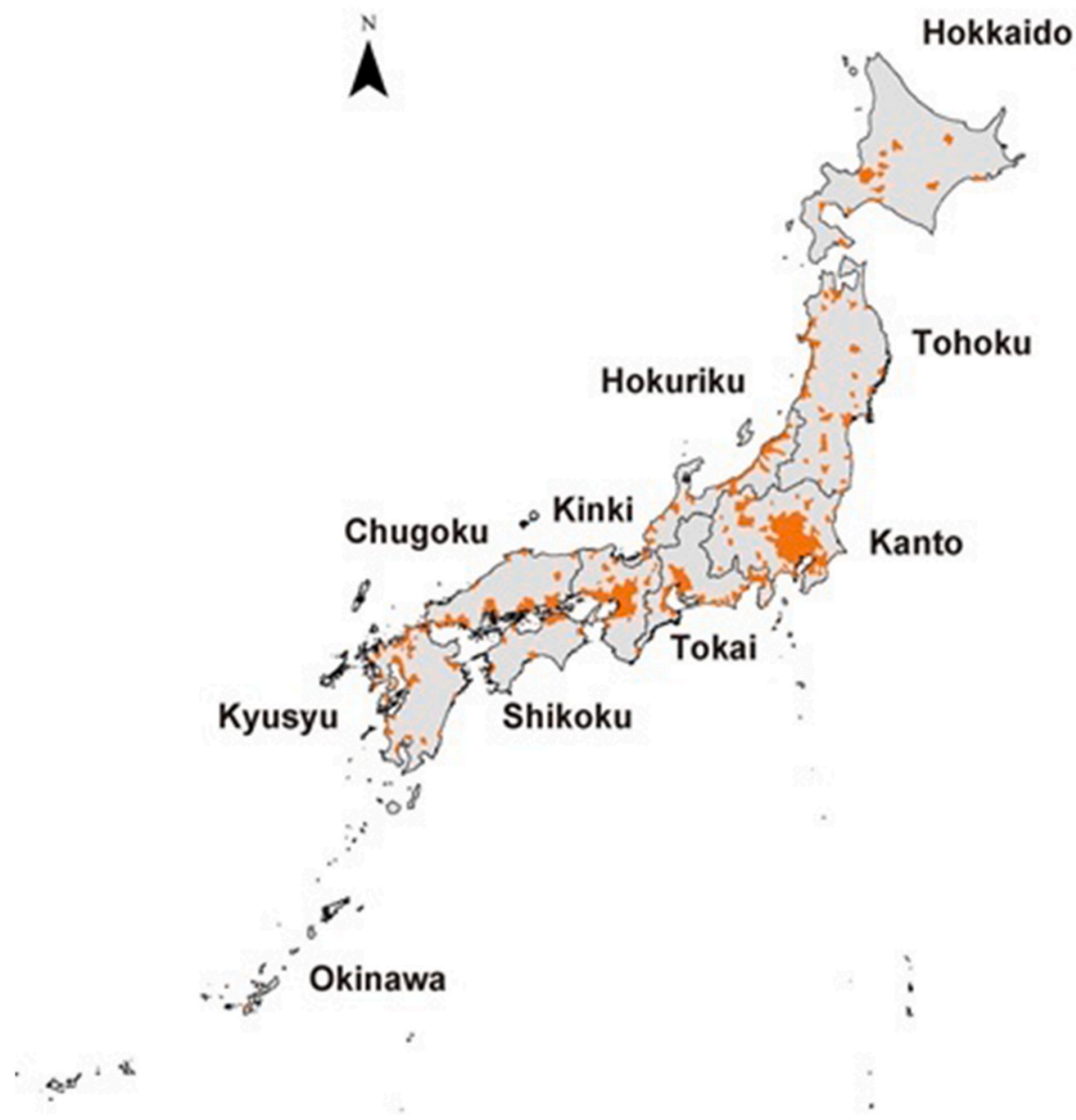

Fig. 7. City gas availability in Japan. Note: Areas where city gas is available are denoted in orange. This figure was created based on the map provided by the Agency for Natural Resources and Energy, Japan ${ }^{8}$.

analysis of the role that new energy-related technologies shall play in EP vulnerability. For this analysis, efficiency, cost and quality are the three vulnerability factors analysed as drivers to EP (see Section 3 for further details).

Efficiency: Inadequate use of housing systems and/or new technologies depends on several diverse factors, including education, culture, social status, location (in terms of information access) and cost awareness [72]. Goedhart et al. [73] showed that socio-economic factors and gender are key aspects to be considered by policymakers when defining policies for the implementation of ICT devices. Yadav et al. [74] established the relevance of education and user satisfaction in ensuring efficient and sustained use of technology through a case study on solar energy systems.

As a Japanese example, this study uses the case of electronic toilets. Electronic toilets do not belong to a low-carbon or energy-saving technology; however, the case is very representative in this context, as they are extensively used, and their inappropriate use may lead to excessive energy consumption. In Japan, the toilet seat warming apparatus is a prevailing technology, that is generally meant to be used in winter. However, it is said that a considerable number of people (specifically the elderly) do not use this system properly. They neglect to turn off the power and consequently warm the toilet seat throughout the year, either due to digital illiteracy or laziness, leading to excessive or unnecessary energy consumption [75]. Fig. 8 illustrates the relationship between low-income households and an inadequate use of the warming toilet seat by means of the question on, 'turning off the warming-seat function except in the winter season'. ${ }^{9}$ The results show that those households with lower income levels have a lower percentage of respondents who answered 'YES' (66\% of the lowest income-level households [their annual income is below 2.5 million Japanese yen] versus $76 \%$ of the highest income-level households [above 20 million Japanese yen]), showing the relationship of inefficient usage of housing systems and/or technology with households' socioeconomic factors, and the role of the digital divide in the risk of EP [76].

Furthermore, highlighting the role of culture, and that of social and cost awareness in the risk of suffering EP in the Japanese context, Yagita et al. [37] showed a lack of willingness among the elderly to use more energy efficient systems even if they are available (see Section 2 for further details).

Cost: The role that income and educational levels play in the effectiveness of new and low-carbon systems implementation was shown by

\footnotetext{
${ }^{8}$ Agency for Natural Resources and Energy, Japan. Link to the website: https ://www.enecho.meti.go.jp/about/special/tokushu/denryokugaskaikaku/gask aikaku.html.

9 Authors' own calculations by using anonymised information from the 2017 Survey on the Actual Conditions of Carbon Dioxide Emissions from Residential Sector, provided by the Ministry of the Environment, Japan [65].
} 


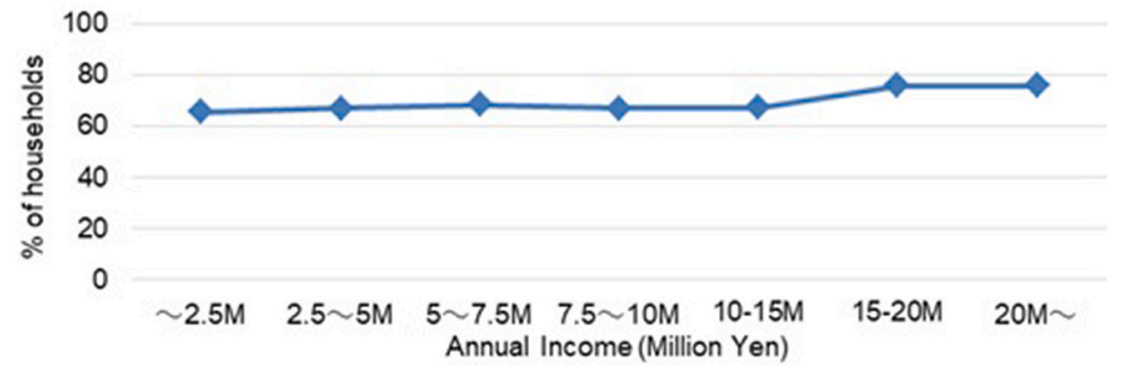

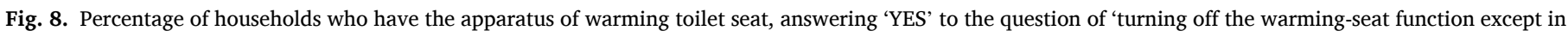
the winter season'.

Yadav et al. [74]. The results suggested that the low income and educational levels of households are negatively related to the willingness to adopt solar panels. Furthermore, the results showed that there is no linear relationship between the desire to progress in the energy ladder (i.e. consumers will move to a more advanced energy system as their incomes increase [77]) and receiving a solar home system free of cost, suggesting that it is not only a matter of providing free access to better energy systems but a matter of social awareness and people's engagement $[37,78]$.

Chapman and Okushima [13] argued that the Japanese government should promote the use of solar panels, or solar energy itself, for the benefit of households in EP in order to engender an inclusive low-carbon energy transition. Solar home systems would help households in EP to reduce their energy expenditure, providing a reliable solution to include them in the low-carbon energy transition without health and environmental issues. In Japan, there is no public support for solar panels installation for energy-poor or low-income households, which leads to inadequate distribution of the large benefits produced by the use of solar panels through the Japanese benevolent feed-in tariff (FIT) system $[13]^{10}$. Currently, households in EP are not considered in the FIT system (a representative low-carbon energy transition policy in Japan) and, consequently, they are excluded from the ongoing low-carbon energy transition.

Fig. 4 and Fig. 6 show that the deployment levels of solar panels are unequally distributed across different regions, and that regions with lower income levels (as well as higher rates of EP) have lower rates of solar panels deployment (e.g. 2.6\% in Hokkaido and 3.9\% in Okinawa), despite their favourable climatic conditions. Additionally, Fig. 9 illustrates the deployment level of the Home Energy Management System (HEMS), an energy-saving technology, for each region. ${ }^{11}$ Although the Japanese government has encouraged a broad use of HEMS for all households to reduce energy consumption in the residential sector, HEMS tends to be introduced only in newly built houses with younger householders [79]. Fig. 9 shows that while currently only a few households use HEMS in Japan (average of 2\%), the deployment rates are lower in the northernmost and southernmost regions (Hokkaido, Tohoku and Okinawa), with the highest EP rates. On the other hand, more developed and central regions (Kanto, Tokai and Kinki) have relatively higher deployment levels of HEMS and lower EP rates. In this respect, it could be stated that an increased use of HEMS (by making it affordable and accessible for the most vulnerable groups) would enable households in EP to reduce their energy consumption and bills and, consequently, improve their empowerment. However, this must be implemented along with effective information and communication

\footnotetext{
${ }^{10}$ For further details on the FIT system in Japan, see the webpage of Agency for Natural Resources and Energy, Japan. https://www.enecho.meti.go.jp/cate gory/saving_and_new/saiene/kaitori/surcharge.html.

11 Authors' own calculations by using anonymised information from the 2017 Survey on the Actual Conditions of Carbon Dioxide Emissions from Residential Sector, provided by the Ministry of the Environment, Japan [65].
}

strategies that address the lack of willingness to adopt such new systems among elderly and groups with low educational levels $[37,78]$.

Quality: New technologies are not always properly designed to cover the required needs of the most vulnerable people. In Japan, it is known that ICT devices should be promoted among the elderly, low-income and female populations, who are considered as the 'have-nots' [80] and as being most vulnerable to EP. Similarly, Lee and Shepley [81] argued the need for further research when implementing new housing systems that aim to reduce energy consumption, specifically for vulnerable people. In Japan, the elderly are likely to retain outdated and energy-inefficient home appliances because of their familiarity, even if they can afford to buy new and efficient ones [37]. In another case, the use of a 24-h circulation bath equipment, considered non-requisite for single- or two-member elderly households, often leads them to have high energy consumption [75]. These are clear examples of new technologies that have been developed without considering the needs of the most vulnerable people. Thus, solutions and policies should no longer have a solely technical focus and rather need to promote social justice and inclusive and human-centric transition [82]. In this respect, Ramsden [83] argued the role of household-level face-to-face advice and support to mitigate the risk of EP among most vulnerable people by assisting them in reducing energy costs and improving energy efficiency.

\subsection{Limitations}

In this subsection, the limitations of the analysis are discussed. First, the analysis in Section 4 aims to identify the vulnerability factors that are associated with regional and seasonal EP prevalence through a graphical representation of the data. However, the results indicate a correlation, without controlling for other factors, and not being intended to establish a causal relation in a rigorous sense. In this sense, further studies need to delve deeper into the proposed relationships using, for instance, panel data with information on more detailed socioeconomic situation of households, their dwelling characteristics, locations, etc.; which can explain the underlying mechanisms behind these relationships.

A further limitation is the poor data availability, which may be partly due to the lack of recognition of EP as a social or political problem in Japan. Unlike in Europe, there has been no policy agenda on EP in Japan, due to which no official statistics and indicators of EP are available historically and currently. As a developed nation, Japan has a wide variety of official statistics. However, as shown in Section 2, academic researchers can evaluate the prevalence of EP only by using unpublicised governmental data that have not been explicitly collected for EP studies.

Finally, this study uses an adapted version of the $10 \%$ measure to evaluate the regional and seasonal characteristics of EP in Japan. Although the choice is reasonable, given the research objective and data availability, the limitations of using the $10 \%$ measure explained in Section 2 will also apply to this study. An EP vulnerability study using other types of EP measures is a focus area for future work. 


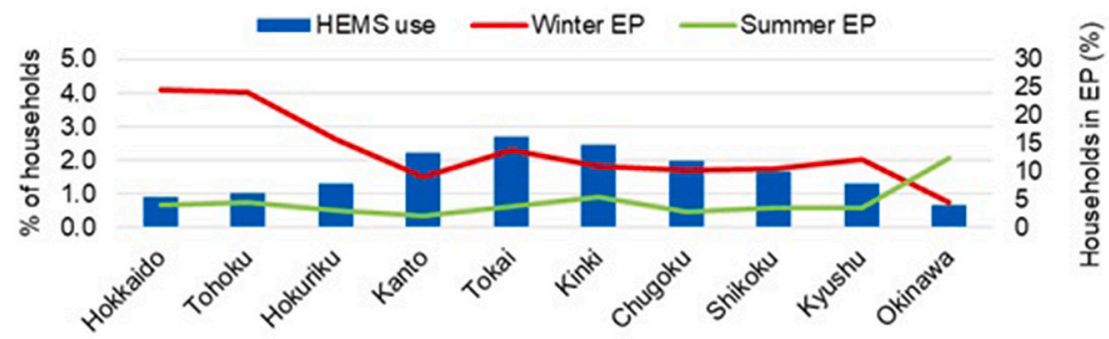

Fig. 9. Regional and seasonal EP rates with respect to the HEMS use (regional disparity in HEMS use).

\section{Discussion}

This section is based on the analysis developed above, and on the researchers' experiences of how EP is experienced in Japan, in order to propose several policy implications. The new theoretical approach proposed in this study is also discussed for a better understanding of the vulnerability factors to EP in Japan (Fig. 1).

In terms of affordability, it is of vital importance to implement policies for the three main features of EP in developed countries: Low incomes, high energy prices, and inadequate levels of housing energy efficiency $[1,4,38]$. While such countermeasures have already been implemented in several European countries (for instance, the National Strategy against Energy Poverty was approved in Spain in 2019 [84]), Japan has implemented no such measures to explicitly address the EP issues, focusing solely on traditional welfare policies such as income support for monetary-poor households. In this respect, the EU's experiences could be considered as a model, mainly due to its history in addressing EP issues. Recently, the European Commission approved the European Green Deal mechanism, which emphasises the need to address the issue of EP in the context of a low-carbon energy transition, without leaving any one behind [85]. The member states were directed to implement effective measures for developing energy-efficiency renovation, which could help households reduce their energy bills and the risk of suffering EP [85]. In the Japanese context, where many households live in old and poor-quality dwellings with high levels of energy expenditure (see Fig. 5 for details), enhancing the energy efficiency of dwellings through retrofitting, or in some cases providing energy-efficient social housing for the energy poor, is considered some of the best policies for addressing EP, with the co-benefit of carbon mitigation, which has been supported by previous Japanese studies [10, $11,32]$. However, an important issue that has recently been exposed is the lack of feasible metrics to assess the effectiveness of such retrofit policies in the context of EP mitigation. Retrofitted dwellings with better energy-efficiency characteristics can negatively lead low-income households to be displaced (i.e. retrofitted housing in the renting sector may become less affordable due to price increases), possibly increasing social exclusion and jeopardising EP mitigation [86]. In this respect, a better understanding of the effectiveness of household retrofit policy is needed to avoid jeopardising EP mitigation and to help stimulate public and private investment [87] (see Section 4.2.1 for further details on the potential for energy-efficiency interventions).

When considering affordability and accessibility, as mentioned in Section 4.2, the Japanese government should promote the use of solar panels, or solar energy itself, among the most vulnerable groups by providing financial support or in-kind contributions. Fig. 10, based on the concept of circular economy, shows the benefits of supporting the use of solar panels among vulnerable groups. According to the Japanese FIT system, only those households (relatively wealthy people) who had installed solar panels (especially at the early stage) by investing their own monetary resources could benefit from the FIT system. The regime must therefore be revised by addressing existing critical barriers, such as providing financial support to low-income households for solar system installation [88].

In the context of energy transition and EP mitigation, the government should promote access to solar energy among the most vulnerable groups to make the energy transition more inclusive [13]. As presented in Fig. 10, promoting the use of solar energy among the most vulnerable households could not only assist them to pay their energy bills but also to increase their empowerment, ensuring an inclusive low-carbon transition. This strategy would improve the household monetary situation (as they reduce their energy expenditure), quality of life, and social relationships (they might afford those basic needs that they could not fulfil before due to the lack of monetary resources), leading to a reduction in $\mathrm{EP}$ and, consequently, a possible reduction in public spending for

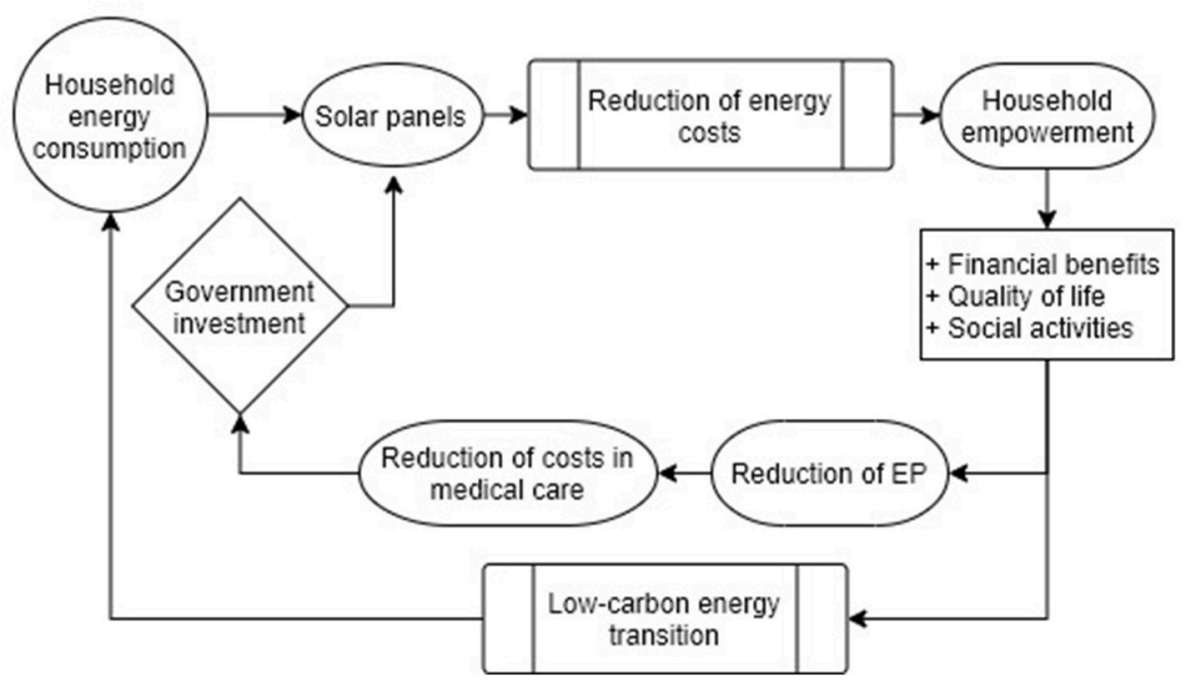

Fig. 10. Graphical analysis: Benefits of supporting solar panels use among the most vulnerable groups. 
medical care. As Castaño-Rosa et al. [89] reported, the potential cost savings in medical care would enable the government to allocate more budget to the promotion of renewable energy solutions among the vulnerable population, as well as financial support for energy-poor people during severe weather periods, that is, cold fronts in winter and heat waves in summer.

Similarly, a Korean case study showed the benefits of promoting solar systems for low-income people in social housing [81], highlighting the importance of supporting non-conventional renewable resources to avoid surcharges in electricity tariffs and, consequently, reducing the risk of EP [90].

Additionally, the promotion of biomass energy (e.g. locally produced firewood) could also reduce (winter) EP in suitable areas. In Japan, some households, specifically living around mountainous areas, use woodstoves for winter heating. However, its high-cost installation and the efforts required for day-to-day management are major bottlenecks in ensuring their widespread use. ${ }^{12}$ Thus, the promotion of woodstoves (i. e. by supporting households in adopting high-efficiency and easy-tomaintain woodstoves and chimneys) may become a valuable practice for some local governments to address (winter) EP, adding to the potential benefits of carbon mitigation and forest conservation.

Finally, the strategy proposed in Fig. 10 is not only concerned with promoting the accessibility of most vulnerable people to solar panels but also the associated reduction of energy costs for the households, leading to their empowerment and a better quality of life. The same process can be applied to the promotion of biomass energy and energy-efficiency measures. Furthermore, the government budget saved, mainly due to the reduction of costs in medical care, can also be used to promote an inclusive low-carbon energy transition by providing financial support to most vulnerable households.

With regard to accessibility, the government is required to bridge the gap in access to low(er)-carbon energy at regional and household levels. Energy access issues are traditionally considered as the problem associated with developing countries and rural areas, where there is a lack of infrastructural development, while a new form of energy access issue is now emerging in the case of low-carbon energy transition: access to lowcarbon energy systems or technology [49-52]. In this context, Fig. 6a presents the relationship between the accessibility of lower-carbon energy systems (by means of lower-carbon energy, such as solar energy and natural gas) and EP prevalence across Japan; Those regions with difficulties in accessing natural gas and installing solar panels have higher EP rates. Natural gas (city gas) is cheaper and lower-carbon energy than LPG, which gives people living in gas-grid areas a significant advantage in addressing the risk of suffering EP, though a higher carbon pricing in the future. Such inequality regarding access to lower-carbon energy systems is becoming more prominent as an energy justice issue in the upcoming deep carbon mitigation era, not only in Japan but across the world.

Additionally, as shown in Fig. 4a, Fig. 6a and Fig. 6d, those people who live in areas with low levels of urbanisation, lack of adequate energy services, and low-income levels have the risk of being isolated, possibly triggering social exclusion [91]. This is related to a new tendency in which young people are moving to big cities where they can have access to new infrastructure and better living conditions, resulting in a continuous reduction in the size of smaller cities, loss of inhabitants and increase in social exclusion [92,93]. Jeon and Kim [92] investigated the main factors that trigger shrinking cities in the East Asian context, highlighting the loss of services and infrastructure, increasing the elderly population, concentration of low-quality houses, poor urban development, lack of indiscriminate redevelopment projects, and promotion of new built-up area projects, as key push and pull factors for

\footnotetext{
${ }^{12}$ For this paragraph, this study is indebted to the personal communication from the staff of Nishiwaga Town, which is famous for woodstove promotion policy (http://www.town.nishiwaga.lg.jp/).
}

people's movement. Thus, social and housing policies should be jointly defined in order to address these hidden issues that could worsen in the forthcoming years in a fast-developing world.

When analysing the new technologies factor, it should be highlighted that the thought that promoting the use of new technologies will improve people's quality of life and, consequently, reduce the risk of suffering EP could be an erroneous assumption if considering cross factors, such as educational level and consumer behaviour. As shown in Fig. 6c, and underpinned by Yagita et al. [37] and Yadav et al. [74], there is a strong relationship between household socioeconomic factors (educational levels, culture, etc.) and the risk of suffering EP. This means that special attention is necessary when defining social policies to address EP, as this process can no longer be solely focused on technology [94]. These polices should not only include financial support but also social attendance (for instance, formation and information), which would improve their understanding of how to effectively manage the measures that are being provided [46,78]. As these vulnerable groups mainly comprise elderly and single-mother households in Japan, they may require further support with their day-to-day activities, relating to domestic energy services use [37,81]. In this respect, as has been established in different European countries (for instance, Spain), social workers play a key role in the detection and monitoring of EP, interacting with households on a daily basis [95]. Japan can also draw on these best practices. However, as a matter of priority for Japan, EP needs to be included in the policy agenda, as in European countries [96,97].

\section{Conclusions}

EP, defined as the inability to fulfil adequate levels of domestic energy services, has been analysed in Japan in previous research. However, there is no in-depth analysis of the contextual factors of EP, and relevant aspects of this issue have been overlooked. This paper goes beyond the current research available and assesses the seasonal and regional characteristics of Japanese EP using an extended version of the multiple-indicator approach defined by Castaño-Rosa et al. [3]. This study builds on several issues unexplored in previous EP studies, such as the regional disparity in access to low(er)-carbon energy systems and the role of new technologies.

The study reveals a higher EP prevalence in the northern regions during winter and in the southernmost region of Okinawa during summer. Additionally, the results highlight location, infrastructure availability, area density and household socioeconomic characteristics as being relevant factors that influence the risk of EP in Japan. Energy infrastructure inequalities have traditionally been overlooked as a possible cause of EP and/or energy deprivation in Japan. Furthermore, it has been highlighted that the use of new technologies may not always improve people's quality of life and, consequently, may not reduce the risk of EP, specifically when considering related factors, such as efficiency (the way in which people use new and low-carbon [energysaving] housing systems), cost (the ability of people to afford new and low-carbon [energy-saving] housing systems), and quality (the effectiveness of new and low-carbon [energy-saving] housing systems in reducing the risk of EP). Finally, this study suggests that, based on the concept of circular economy, the government should promote vulnerable households' access to renewable energy systems (specifically solar power and biomass), distributing the benefit of renewable-energy deployment more evenly and fairly. This would lead to a reduction in $\mathrm{EP}$ and, consequently, might lead to a reduction in medical care costs and an increase in public financial support to assist most vulnerable people (as graphically shown in Fig. 10), as well as a participation increase of vulnerable groups in the ongoing low-carbon transition process (inclusiveness).

This study not only provides a novel approach to better understand EP vulnerability in Japan but also provides potential implications for properly implementing current strategies at the EU level. For instance, the EU Green Deal emphasises the need to address the issue of EP in the 
context of a low-carbon energy transition and changing climate, without leaving any one behind. The theoretical approach proposed in this study covers social-related issues within developed and developing countries (i.e. income level, educational and cultural factors, rural area isolation, shrinking cities, etc.), identifying similarities among most vulnerable groups and prioritisation areas such as the promotion of affordable and low-carbon energy systems among rural areas (it is well known to be a common issue in most European countries) [98,99]. Furthermore, this study indicates that the development of effective information and communication strategies is required, avoiding the exclusion of most vulnerable people who do not have access to (new) information channels (elderly, people with low education level, etc.) [100].

Finally, it is important to note that given the limited understanding of EP vulnerability in Japan, this study provides a comprehensive approach to understand the risk of EP in Japan, enabling national and local governments to develop effective social policies. However, these results should be viewed as indicative, thus highlighting the need for further research on designing detailed schemes and verifying the efficacy of the proposed approach. The authors hope that the findings will contribute to the scholarship on EP in Japan, and the promotion of future practices in addressing EP across the world.

\section{Author contributions}

Raúl Castaño-Rosa: Conceptualization, Methodology, Validation, Formal analysis, Investigation, Writing - Original Draft, Writing - Review \& Editing, Visualization, Supervision. Shinichiro Okushima: Conceptualization, Methodology, Validation, Formal analysis, Investigation, Writing - Original Draft, Writing - Review \& Editing, Visualization, Supervision, Funding acquisition.

\section{Funding}

This research was supported by the Grant-in-Aid for Scientific Research (JSPSKAKENHI) [Grant No. JP17K00679].

\section{Declaration of competing interest}

The authors declare that they have no known competing financial interests or personal relationships that could have appeared to influence the work reported in this paper.

\section{Acknowledgments}

The authors would like to thank the staff of Statistics Bureau, Ministry of Internal Affairs and Communications, those of Ministry of the Environment, those of Nishiwaga Town, and Masaya Tokutake for their kind assistance with this study.

\section{References}

[1] Bouzarovski S, Petrova S. A global perspective on domestic energy deprivation: overcoming the energy poverty-fuel poverty binary. Energy Research and Social Science 2015;10:31-40. https://doi.org/10.1016/j.erss.2015.06.007.

[2] European Commission. EU energy poverty observatory (CN ENER/B3/SER/2015 507/SI2.742529). 2018. https://www.energypoverty.eu/. [Accessed 16 September 2020].

[3] Castaño-Rosa R, Solís-Guzmán J, Rubio-Bellido C, Marrero M. Towards a multiple-indicator approach to energy poverty in the European Union: a review. Energy Build 2019;193:36-48. https://doi.org/10.1016/j.enbuild.2019.03.039.

[4] Bouzarovski S. Energy Poverty: (Dis)Assembling Europe's Infrastructural Divide. Switzerland: Palgrave Macmilan; 2018.

[5] Teschner N, Sinea A, Vornicu A, Abu-Hamed T, Negev M. Extreme energy poverty in the urban peripheries of Romania and Israel: policy, planning and infrastructure. Energy Research and Social Science 2020;66:101502. https://doi. org/10.1016/j.erss.2020.101502.

[6] Daniel L, Baker E, Beer A, Pham NTA. Cold housing: evidence, risk and vulnerability. Hous Stud 2019;1-21. https://doi.org/10.1080/ 02673037.2019.1686130.
[7] Baker E, Pham NTA, Daniel L, Bentley R. New evidence on mental health and housing affordability in cities: a quantile regression approach. Cities 2020;96: 102455. https://doi.org/10.1016/j.cities.2019.102455.

[8] Hajat S. Health effects of milder winters: a review of evidence from the United Kingdom. Environ Health 2017;16:109. https://doi.org/10.1186/s12940-0170323-4.

[9] Zhang X, Norbäck D, Fan Q, Bai X, Li T, Zhang Y, et al. Dampness and mold in homes across China: associations with rhinitis, ocular, throat and dermal symptoms, headache and fatigue among adults. Indoor Air 2019;29:30-42. https://doi.org/10.1111/ina.12517.

[10] Okushima S. Measuring energy poverty in Japan, 2004-2013. Energy Pol 2016; 98:557-64. https://doi.org/10.1016/j.enpol.2016.09.005.

[11] Okushima S. Gauging energy poverty: a multidimensional approach. Energy 2017;137:1159-66. https://doi.org/10.1016/j.energy.2017.05.137.

[12] Okushima S. Understanding regional energy poverty in Japan: a direct measurement approach. Energy Build 2019;193:174-84. https://doi.org/ 10.1016/j.enbuild.2019.03.043.

[13] Chapman A, Okushima S. Engendering an inclusive low-carbon energy transition in Japan: considering the perspectives and awareness of the energy poor. Energy Pol 2019;135:111017. https://doi.org/10.1016/j.enpol.2019.111017.

[14] Zhang D, Li J, Han P. A multidimensional measure of energy poverty in China and its impacts on health: an empirical study based on the China family panel studies. Energy Pol 2019;131:72-81. https://doi.org/10.1016/j.enpol.2019.04.037.

[15] Lin B, Wang Y. Does energy poverty really exist in China? From the perspective of residential electricity consumption. Energy Pol 2020;143:111557. https://doi. org/10.1016/j.enpol.2020.111557.

[16] Fuller S, Barber LB, Mah DN. Narratives of energy poverty in Hong Kong. Energy Build 2019;191:52-8. https://doi.org/10.1016/j.enbuild.2019.03.015.

[17] Nathan HSK, Hari L. Towards a new approach in measuring energy poverty: household level analysis of urban India. Energy Pol 2020;140:111397. https:// doi.org/10.1016/j.enpol.2020.111397.

[18] Acharya RH, Sadath AC. Energy poverty and economic development: householdlevel evidence from India. Energy Build 2019;183:785-91. https://doi.org/ 10.1016/j.enbuild.2018.11.047.

[19] OECD. OECD Reviews of Public Health: Japan: A Healthier Tomorrow. Paris: OECD; 2019. https://doi.org/10.1787/9789264311602-en.

[20] Ministry of Health, Labour and Welfare, Japan. 2014 Annual Health, Labour and Welfare Report. Tokyo; 2014. https://www.mhlw.go.jp/english/wp/wp-hw8/i ndex.html.

[21] Nomura S, Sakamoto H, Glenn S, Tsugawa Y, Abe SK, Rahman MM, et al. Population health and regional variations of disease burden in Japan, 1990-2015: a systematic subnational analysis for the Global Burden of Disease Study 2015 Lancet 2017;390:1521-38. https://doi.org/10.1016/S0140-6736(17)31544-1.

[22] Hiyoshi A, Fukuda Y, Shipley MJ, Brunner EJ. Health inequalities in Japan: the role of material, psychosocial, social relational and behavioural factors. Soc Sci Med 2014;104:201-9. https://doi.org/10.1016/j.socscimed.2013.12.028.

[23] Cong S, Araki A, Ukawa S, Ait Bamai Y, Tajima S, Kanazawa A, et al. Association of mechanical ventilation and flue use in heaters with asthma symptoms in Japanese schoolchildren: a cross-sectional study in Sapporo, Japan. J Epidemiol 2014;24(3):230-8. https://doi.org/10.2188/jea.je20130135.

[24] Li K, Lloyd B, Liang XJ, Wei YM. Energy poor or fuel poor: what are the differences? Energy Pol 2014;68:476-81. https://doi.org/10.1016/j. enpol.2013.11.012.

[25] Bouzarovski S, Petrova S, Tirado-Herrero S. From Fuel Poverty to Eneroy Vulnerability: The Importance of Services, Needs and Practices. SPRU Working Paper Series; 2014. p. 2014-25.

[26] Boardman B. Fuel Poverty: From Cold Homes to Affordable Warmth. London: Belhaven Press; 1991.

[27] Rademaekers K, Yearwood J, Ferreira A, Pye S, Hamilton I, Agnolucci P, et al. Selecting Indicators to Measure Energy Poverty. Rotterdam: Trinomics; 2016.

[28] Betto F, Garengo P, Lorenzoni A. A new measure of Italian hidden energy poverty. Energy Pol 2020;138:111237. https://doi.org/10.1016/j.enpol.2019.111237.

[29] Dubois U. From targeting to implementation: the role of identification of fuel poor households. Energy Pol 2012;49:107-15. https://doi.org/10.1016/j. enpol.2011.11.087.

[30] Meyer S, Laurence H, Bart D, Lucie M, Kevin M. Capturing the multifaceted nature of energy poverty: lessons from Belgium. Energy Research and Social Science 2018;40:273-83. https://doi.org/10.1016/j.erss.2018.01.017.

[31] McCauley D, Heffron R. Just transition: integrating climate, energy and environmental justice. Energy Pol 2018;119:1-7. https://doi.org/10.1016/j. enpol.2018.04.014.

[32] Konno Y, Mori T, Iwama Y. Research on actual condition of fuel poverty in Hokkaido. J Environ Eng 2018;83(751):729-36.

[33] Tabata T, Tsai P. Fuel poverty in Summer: an empirical analysis using microdata for Japan. Sci Total Environ 2020;703:135038. https://doi.org/10.1016/j. scitotenv.2019.135038.

[34] Statistics Bureau, Ministry of Internal Affairs and Communications, Japan. http s://www.stat.go.jp/english/.

[35] Tokyo Metropolitan University Research Center for Child and Adolescent Poverty Report of Tokyo Prefecture Child Living Conditions Survey (on Elementary, Junior and Senior High School Children). Tokyo; 2017.

[36] National Institute of Population and Social Security Research. Report of National Survey on Social Security and People's Life 2017. Tokyo; 2019.

[37] Yagita Y, Kawai T, Iwafune Y. Current situation and issues on energy use of aged households. In: Proceedings of the 35th conference on energy, economy, and environment; 2019. 292-7. 
[38] Boardman B. Fixing Fuel Poverty: Challenges and Solutions. London: Earthscan; 2010.

[39] Robinson C, Lindley S, Bouzarovski S. The spatially varying components of vulnerability to energy poverty. Ann Assoc Am Geogr 2019:1-20. https://doi. org/10.1080/24694452.2018.1562872.

[40] Kearns A, Whitley E, Curl A. Occupant behaviour as a fourth driver of fuel poverty (aka warmth \& energy deprivation). Energy Pol 2019;129:1143-55. https://doi org /10.1016/j.enpol.2019.03.023.

[41] Scarpellini S, Hernández MAS, Moneva JM, Portillo-Tarragona P, Rodríguez MEL. Measurement of spatial socioeconomic impact of energy poverty. Energy Pol 2019;124:320-31. https://doi.org/10.1016/j.enpol.2018.10.011.

[42] Longhurst N, Hargreaves T. Emotions and fuel poverty: the lived experience of social housing tenants in the United Kingdom. Energy Research and Social Science 2019;56:101207. https://doi.org/10.1016/j.erss.2019.05.017.

[43] Sanz-Hernández A. Social engagement and socio-genesis of energy poverty as a problem in Spain. Energy Pol 2019;124:286-96. https://doi.org/10.1016/j. enpol.2018.10.001.

[44] Ortiz J, Casquero-Modrego N, Salom J. Health and related economic effects of residential energy retrofitting in Spain. Energy Pol 2019;130:375-88. https://doi org/10.1016/j.enpol.2019.04.013.

[45] Castaño-Rosa R, Sherriff G, Thomson H, Guzmán JS, Marrero M. Transferring the index of vulnerable homes: application at the local-scale in England to assess fuel poverty vulnerability. Energy Build 2019;203:109458. https://doi.org/10.1016/ j.enbuild.2019.109458.

[46] Baker KJ, Mould R, Stewart F, Restrick S, Melone H, Atterson B. Never try and face the journey alone: exploring the face-to-face advocacy needs of fuel poor householders in the United Kingdom. Energy Research and Social Science 2019; 51:210-9. https://doi.org/10.1016/j.erss.2019.01.009.

[47] Hansen AR, Jacobsen MH. Like parent, like child: intergenerational transmission of energy consumption practices in Denmark. Energy Research and Social Science 2020;61:101341. https://doi.org/10.1016/j.erss.2019.101341.

[48] Bouzarovski S, Simcock N. Spatializing energy justice. Energy Pol 2017;107: 640-8. https://doi.org/10.1016/j.enpol.2017.03.064.

[49] Sovacool BK, Kester J, Noel L, de Rubens GZ. Energy injustice and nordic electric mobility: inequality, elitism, and externalities in the electrification of vehicle-togrid (V2G) transport. Ecol Econ 2019;157:205-17. https://doi.org/10.1016/j. ecolecon.2018.11.013.

[50] Sovacool BK, Turnheim B, Hook A, Brock A, Martiskainen M. Dispossessed by decarbonisation: reducing vulnerability, injustice, and inequality in the lived experience of low-carbon pathways. World Dev 2021;137:105116. https://doi. org/10.1016/j.worlddev.2020.105116.

[51] Johnson OW, Han JY-C, Knight A-L, Mortensen S, Aung MT, Boyland M, et al. Intersectionality and energy transitions: a review of gender, social equity and low-carbon energy. Energy Research and Social Science 2020;70:101774. https:// doi.org/10.1016/j.erss.2020.101774.

[52] Sovacool BK, Lipson MM, Chard R. Temporality, vulnerability, and energy justice in household low carbon innovations. Energy Pol 2019;128:495-504. https://doi. org/10.1016/j.enpol.2019.01.010.

[53] Anderson W, White V. "You just have to get by" Coping with low incomes and cold homes. Bristol: Centre for Sustainable Energy; 2019.

[54] Beatty TKM, Blow L, Crossley TF. Is there a 'heat-or-eat' trade-off in the UK? J Roy Stat Soc 2014;177(1):281-94. http://www.jstor.org/stable/43965682.

[55] OECD. OECD Regions at a Glance 2016. Paris: OECD; 2016. https://doi.org/10.17 87/reg glance-2016-en.

[56] Castaño-Rosa R, Solís-Guzmán J, Marrero M. A novel index of vulnerable homes: findings from application in Spain. Indoor Built Environ 2020;29(3):311-30. https://doi.org/10.1177/1420326X18764783.

[57] European Parliament. Council of the European Union. Directive 2009/72/EC of the European Parliament and of the Council of 13 July 2009 concerning common rules for the internal market in electricity and repealing Directive 2003/54/EC. 2009.

[58] Pierse N, Arnold R, Keall M, Howden-Chapman P, Crane J, Cunningham M. Modelling the effects of low indoor temperatures on the lung function of children with asthma. J Epidemiol Community Health 2013;67:918-25. https://doi.org/ 10.1136/jech-2013-202632.

[59] März S. Assessing the fuel poverty vulnerability of urban neighbourhoods using a spatial multi-criteria decision analysis for the German city of Oberhausen. Renew Sustain Energy Rev 2018;82:1701-11. https://doi.org/10.1016/j. rser.2017.07.006.

[60] Petrova S, Simcock N. Gender and energy: domestic inequities reconsidered. Soc Cult Geogr 2019;1-19. https://doi.org/10.1080/14649365.2019.1645200.

[61] Boemi S-N, Papadopoulos AM. Energy poverty and energy efficiency improvements: a longitudinal approach of the Hellenic households. Energy Build 2019;197:242-50. https://doi.org/10.1016/j.enbuild.2019.05.027.

[62] Thomson H, Simcock N, Bouzarovski S, Petrova S. Energy poverty and indoor cooling: an overlooked issue in Europe. Energy Build 2019;196:21-9. https://doi. org/10.1016/j.enbuild.2019.05.014.

[63] Castaño-Rosa R, Solís-Guzmán J, Marrero M. Energy poverty goes south? Understanding the costs of energy poverty with the index of vulnerable homes in Spain. Energy Research and Social Science 2020;60:101325. https://doi.org/ 10.1016/j.erss.2019.101325.

[64] Jyukankyo Research Institute. Residential Energy Statistics Yearbook 2017. Tokyo: Jyukankyo Research Institute; 2019.

[65] Ministry of the Environment, Japan. http://www.env.go.jp/earth/ondanka/ghg /kateiCO2tokei.html.
[66] Eurostat. Unemployment rate - annual data. 2019. https://ec.europa.eu/eu rostat $/ \mathrm{tgm} /$ table.do?tab=table\&init=1\&language $=$ en \&pcode=tipsun20\&plugin $=1$. [Accessed 28 March 2020].

[67] Harker L. Chance of a lifetime: The impact of housing on children's lives. London: Shelter; 2006.

[68] Middlemiss L. Chapter 5 - Energy poverty: Understanding and addressing systemic inequalities. In: Galvin R, editor. Inequality and Energy. London: Academic Press; 2020. p. 99-114. https://doi.org/10.1016/B978-0-12-817674-0 .00005-9.

[69] Robinson C, Bouzarovski S, Lindley S. 'Getting the measure of fuel poverty': the geography of fuel poverty indicators in England. Energy Research and Social Science 2018;36:79-93. https://doi.org/10.1016/j.erss.2017.09.035.

[70] Bouzarovski S, Thomson H. Energy vulnerability in the grain of the city: toward neighborhood typologies of material deprivation. Ann Assoc Am Geogr 2017; 1-23. https://doi.org/10.1080/24694452.2017.1373624.

[71] González-Eguino M. Energy poverty: An overview. Renew Sustain Energy Rev 2015. https://doi.org/10.1016/j.rser.2015.03.013.

[72] Wagner O, Wiegand J. Prepayment metering: household experiences in Germany. Renew Sustain Energy Rev 2018;98:407-14. https://doi.org/10.1016/j. rser.2018.09.025.

[73] Goedhart NS, Broerse JEW, Kattouw R, Dedding C. 'Just having a computer doesn't make sense': the digital divide from the perspective of mothers with a low socio-economic position. New Media Soc 2019;21:2347-65. https://doi.org/ 10.1177/1461444819846059.

[74] Yadav P, Davies PJ, Sarkodie SA. The prospects of decentralised solar energy home systems in rural communities: user experience, determinants, and impact of free solar power on the energy poverty cycle. Energy Strategy Reviews 2019;26: 100424. https://doi.org/10.1016/j.esr.2019.100424.

[75] Yagita Y, Iwafune Y. Characteristics and improving ways of elderly households with high energy consumption. Proceedings of the 36th Conference on Energy, Economy, and Environment 2020. 203-6.

[76] Nicholls L, Strengers Y, Sadowski J. Social impacts and control in the smart home. Nature Energy 2020;5:180-2. https://doi.org/10.1038/s41560-020-0574-0.

[77] van der Kroon B, Brouwer R, van Beukering PJH. The energy ladder: theoretical myth or empirical truth? Results from a meta-analysis. Renew Sustain Energy Rev 2013;20:504-13. https://doi.org/10.1016/j.rser.2012.11.045.

[78] Chen C-F, Li J, Shuai J, Nelson H, Walzem A, Cheng J. Linking socialpsychological factors with policy expectation: using local voices to understand solar PV poverty alleviation in Wuhan, China. Energy Pol 2021;151:112160. https://doi.org/10.1016/j.enpol.2021.112160.

[79] Iwafune Y, Yagita Y. High-resolution determinant analysis of Japanese residential electricity consumption using home energy management system data. Energy Build 2016;116:274-84. https://doi.org/10.1016/j.enbuild.2016.01.017.

[80] Ministry of Internal Affairs and Communications. 2011 White Paper on Information and Communications in Japan. Tokyo; 2011.

[81] Lee J, Shepley MM. Benefits of solar photovoltaic systems for low-income families in social housing of Korea: renewable energy applications as solutions to energy poverty. Journal of Building Engineering 2020;28:101016. https://doi.org/ 10.1016/j.jobe.2019.101016.

[82] Pigato M. Information and communication technology, poverty, and development in sub-Saharan Africa and South Asia. Africa Region Working Paper Series No. 20. Washington, D.C.: World Bank; 2001.

[83] Ramsden S. Tackling fuel poverty through household advice and support: exploring the impacts of a charity-led project in a disadvantaged city in the United Kingdom. Energy Research and Social Science 2020;70:101786. https:// doi.org/10.1016/j.erss.2020.101786.

[84] Spanish Government. Ministry for the Ecological Trasition. National Strategy against Energy Poverty 2019-2024 (Royal Decree 15/2018). 2019. Spain.

[85] European Commission. The European Green Deal 2019;24.

[86] Grossmann K. Energy efficiency for whom? : a conceptual view on retrofitting, residential segregation and the housing market. Sociol Urbana Rurale 2019;119: 78-95. https://doi.org/10.3280/SUR2019-119006.

[87] Kerr N, Winskel M. Household investment in home energy retrofit: a review of the evidence on effective public policy design for privately owned homes. Renew Sustain Energy Rev 2020;123:109778. https://doi.org/10.1016/j. rser.2020.109778.

[88] Yaqoot M, Diwan P, Kandpal TC. Review of barriers to the dissemination of decentralized renewable energy systems. Renew Sustain Energy Rev 2016;58: 477-90. https://doi.org/10.1016/j.rser.2015.12.224.

[89] Castaño-Rosa R, Sherriff G, Solís-Guzmán J, Marrero M. The validity of the index of vulnerable homes: evidence from consumers vulnerable to energy poverty in the UK. Energy Sources B Energy Econ Plann 2020;15(2):72-91. https://doi.org/ 10.1080/15567249.2020.1717677.

[90] Mastropietro P. Who should pay to support renewable electricity? Exploring regressive impacts, energy poverty and tariff equity. Energy Research and Social Science 2019;56:101222. https://doi.org/10.1016/j.erss.2019.101222.

[91] Brito-Henriques E, Cruz D. Seeking the causes of urban ruination: an empirical research in four Portuguese cities. Geogr Pol 2019;92:17-35. https://doi.org/ 10.7163/GPol.0134.

[92] Jeon Y, Kim S. Housing abandonment in shrinking cities of East Asia: case study in Incheon, South Korea. Urban Stud 2020;57(8):1749-67. https://doi.org/ $10.1177 / 0042098019852024$.

[93] Murie A. Shrinking the state in housing: challenges, transitions and ambiguities. Camb J Reg Econ Soc 2018;11(3):485-501. https://doi.org/10.1093/cjres/ rsy024. 
[94] Sovacool BK, Griffiths S. The cultural barriers to a low-carbon future: a review of six mobility and energy transitions across 28 countries. Renew Sustain Energy Rev 2020;119:109569. https://doi.org/10.1016/j.rser.2019.109569.

[95] Scarpellini S, Sanz Hernández MA, Llera-Sastresa E, Aranda JA, López Rodríguez ME. The mediating role of social workers in the implementation of regional policies targeting energy poverty. Energy Pol 2017;106:367-75. https:// doi.org/10.1016/j.enpol.2017.03.068.

[96] Wolsink M. Distributed energy systems as common goods: socio-political acceptance of renewables in intelligent microgrids. Renew Sustain Energy Rev 2020;127:109841. https://doi.org/10.1016/j.rser.2020.109841.

[97] Borozan D. Regional-level household energy consumption determinants: the european perspective. Renew Sustain Energy Rev 2018;90:347-55. https://doi. org/10.1016/j.rser.2018.03.038.
[98] Sokołowski J, Lewandowski P, Kiełczewska A, Bouzarovski S. A multidimensional index to measure energy poverty: the Polish case. Energy Sources B Energy Econ Plann 2020;15(2):92-112. https://doi.org/10.1080/15567249.2020.1742817.

[99] Mould R, Baker KJ. Uncovering hidden geographies and socio-economic influences on fuel poverty using household fuel spend data: a meso-scale study in Scotland. Indoor Built Environ 2017;26(7):914-36. https://doi.org/10.1177/ 1420326 X17707326.

[100] Caballero N, Della Valle N. Tackling energy poverty through behavioral change: a pilot study on social comparison interventions in social housing districts. Frontiers in Sustainble Cities 2021;2:66. https://doi.org/10.3389/ frsc. 2020.601095. 